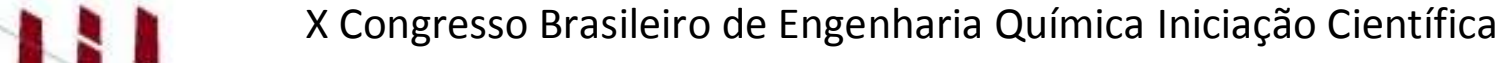 \\ "Influência da pesquisa em Engenharia Química no desenvolvimento tecnológico e industrial brasileiro" \\ Universidade Federal Rural do Rio de Janeiro Universidade Severino Sombra Vassouras - RJ - Brasil
}

\section{EFEITO DA ADIÇÃO DE METAIS INORGÂNICOS NA DECOMPOSIÇÃO TÉRMICA DE BAGAÇO DE SORGO SACARINO}

\author{
CUNHA $^{* 1}$, I. F.; CARVALHO², W. S.; ATAÍDE ${ }^{3}$, C. H. \\ ${ }^{1}$ Aluna da FEQUI/UFU $\quad{ }^{2}$ Doutorando da FEQUI/UFU ${ }^{3}$ Professor da FEQUI/UFU \\ Faculdade de Engenharia Química/Universidade Federal de Uberlândia \\ Endereço - Av. João Naves de Ávila, 2121, Bloco 1K, Campus Santa Mônica, Uberlândia - MG, \\ CEP 38408-100 \\ email: chataide@ufu.br
}

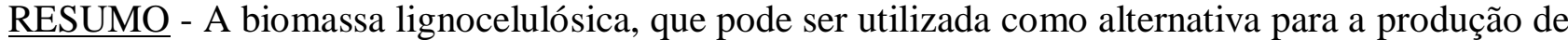
energia através de processos de conversão termoquímica como a pirólise, é uma mistura complexa de polímeros naturais de carboidratos conhecidos como celulose, hemicelulose, além de lignina e pequenas quantidades de outras substâncias. O sorgo sacarino pode complementar a produção da cana de açúcar já que seu crescimento é mais rápido, utiliza menos água e fertilizantes e alcança picos de açúcar em diferentes épocas do ano. Cada tipo de biomassa exibe uma característica particular quando pirolisada devido à proporção dos componentes que a constituem, sendo, portanto de grande importância sua caracterização. O bio-óleo é um combustível altamente oxigenado e ácido, além de ser termicamente instável e não totalmente miscível nos combustíveis oriundos de petróleo. A adição de sais inorgânicos à biomassa é uma das técnicas investigadas para promover o melhoramento da qualidade do bio-óleo. Foi realizado um estudo térmico do sorgo sacarino puro e adicionado com alguns sais, através das curvas de perda de massa (TG) e derivada de perda de massa (DTG), em diferentes taxas de aquecimento. Os resultados mostraram alterações nos parâmetros cinéticos estimados, oriundos dos dados experimentais de decomposição térmica da biomassa com a adição de sais.
\end{abstract}

Palavras chave: biomassa, impregnação de sais, análise termogravimétrica

\section{INTRODUÇÃO}

A demanda por fontes renováveis e menos prejudiciais a natureza é cada vez maior, pois a produção de gases nocivos ao meio ambiente e a saúde humana tem crescido muito nos últimos anos devido à queima de combustíveis fósseis. Uma solução para esse problema é a utilização da biomassa, matéria residual de processos industriais e agrícolas, abundante e por isso de baixo custo (Gianesella, 2010). Uma alternativa muito interessante de biomassa pode ser a utilização do sorgo sacarino, quinto cereal em importância no mundo depois do arroz, milho, trigo e cevada. Essa matéria prima complementa a produção de cana de açúcar e desponta como a cultura ideal para alimentação e também para produção de biocombustíveis de primeira geração como o 
etanol. O sorgo cresce rapidamente, apresenta cultura totalmente mecanizável (plantio por sementes, tratos culturais e colheita), utilizando menos água e fertilizante, alcança picos de açúcar em diferentes épocas do ano e possui alta produtividade de biomassa verde, entre 60 e 80t.ha ${ }^{-1}$ (Linton et al., 2011). Uma das vantagens do sorgo para a produção de etanol, se comparado à cana, são os derivados que a planta gera, como seu bagaço, que apresenta melhor qualidade biológica para o fornecimento na alimentação animal e geração de energia. Outra alternativa que vem sendo bastante estudada é a conversão dessa biomassa em bio-óleo, através de um processo conhecido como pirólise rápida, no qual materiais orgânicos são aquecidos a aproximadamente $500^{\circ} \mathrm{C}$, na ausência de oxigênio. A pirólise pode ser definida como a degradação térmica de um material orgânico na ausência parcial ou total de um agente oxidante, ou até mesmo, em um ambiente com uma concentração de oxigênio capaz de evitar a gaseificação intensiva do material orgânico (Bridgwater et al., 2000). A pirólise rápida tem como principais características curtos tempos de aquecimento das partículas e de residência para os vapores que se formam dentro do reator e que são rapidamente resfriados, altas taxas de aquecimento, elevados coeficientes de transferência de calor e massa, e manutenção cuidadosa da temperatura de reação. Sua principal vantagem em comparação aos outros processos de conversão termoquímica da biomassa é a produção de um derivado líquido (bio-óleo) que pode ser facilmente armazenado e transportado.

O principal objetivo no processo de pirólise é a obtenção de produtos com densidade energética mais alta e melhores propriedades do que aquelas da biomassa original. Esse processo resulta em um conjunto de pequenas espécies moleculares, as quais são relacionadas à composição da matéria prima original (Riegel et al., 2008). Na pirólise, os polímeros lignocelulósicos (hemicelulose, celulose e lignina) são submetidos à clivagem térmica para produzir diferentes componentes químicos que rapidamente vaporizam-se e após condensação tem-se um líquido negro chamado de bio-óleo (Lu et al., 2011a). O processo também produz gás, que pode ser consumido no próprio processo de pirólise e um resíduo orgânico sólido chamado char com algumas aplicações, desde adubo a filtros industriais. $\mathrm{O}$ bio-óleo é um combustível altamente oxigenado, ácido e corrosivo para os metais comuns, além de ser química e termicamente instável, bem como não miscível com combustíveis de petróleo. Algumas técnicas para promover o melhoramento do bio-leo são geralmente empregadas, como a adição de sais inorgânicos à biomassa para favorecer a formação de compostos específicos ou menos oxigenados (Lu et al., 2011b).

Ainda que a biomassa advinda de fontes vegetais consista essencialmente em celulose, hemicelulose e lignina, juntamente com quantidades menores de extrativos, umidade, minerais e matéria, cada tipo de biomassa exibe uma característica particular quando pirolisada devido à proporção dos componentes que formam o material renovável (Yao et al., 2008). Dessa forma, a caracterização ou composição inicial da biomassa assume papel importante na descrição das potencialidades dos processos de termoconversão (Bridgwater et al., 2000). Um método eficaz de estudo das potencialidades de determinada biomassa como insumo para a pirólise é a análise termogravimétrica, uma técnica que mede as variações de massa de um material, em função da temperatura e do tempo, em uma atmosfera controlada e que visa conhecer o comportamento térmico e os parâmetros cinéticos da biomassa durante o processo de termoconversão (Ionashiro, 2005). Os resultados são expressos na forma de curvas de perda de massa (TG) e derivadas de perda de massa (DTG).

O presente trabalho teve como objetivo principal estudar a influência da adição de cloreto de magnésio e cloreto de zinco em diferentes concentrações na decomposição térmica do bagaço de sorgo sacarino, através das curvas de perda de massa (TG) e derivada de perda de massa (DTG).

\section{MATERIAL E MÉTODOS}

\section{Biomassa Utilizada}

Nos testes foi utilizado um híbrido de sorgo sacarino desenvolvido pela Monsanto. 
Os colmos do sorgo foram cortados, esmagados em um moinho de rolos manual para a retirada da maioria do caldo, secos em estufa durante 24 horas e triturados em um moinho de facas para uma posterior classificação granulométrica.

A Tabela 1 apresenta algumas características desse material:

Tabela 1 - Poder calorífico, análise imediata, composição química e análise elementar para o bagaço de sorgo sacarino.

\begin{tabular}{|c|c|c|c|}
\hline $\begin{array}{c}\text { Poder } \\
\text { calorífico }\end{array}$ & $(\mathrm{kcal} / \mathbf{k g})$ & $\begin{array}{c}\text { Análise } \\
\text { imediata }\end{array}$ & $(\%)$ \\
\hline Inferior & 3,765 & Voláteis & 79,30 \\
\hline Superior & 4,069 & Cinzas & 2,99 \\
\hline Útil & 3,141 & $\begin{array}{l}\text { Carbono } \\
\text { fixo }\end{array}$ & 17,71 \\
\hline $\begin{array}{l}\text { Composição } \\
\text { química }\end{array}$ & $(\%)$ & $\begin{array}{c}\text { Análise } \\
\text { elementar }\end{array}$ & $(\%)$ \\
\hline Holocelulose & 39,33 & $\mathrm{C}$ & 41,72 \\
\hline $\begin{array}{l}\text { Lignina } \\
\text { solúvel }\end{array}$ & 1,05 & $\mathrm{~N}$ & 0,55 \\
\hline $\begin{array}{l}\text { Lignina } \\
\text { insolúvel }\end{array}$ & 9,62 & $\mathrm{H}$ & 6,32 \\
\hline Extrativos & 46,08 & $\mathrm{O}$ & 49,50 \\
\hline \multicolumn{4}{|c|}{ Quantidade de elementos inorgânicos } \\
\hline Elemento & $(\%)$ & Elemento & $(\%)$ \\
\hline $\mathrm{K}$ & 4,70 & $\mathrm{~S}$ & 0,13 \\
\hline $\mathrm{Cl}$ & 1,51 & $\mathrm{Zn}$ & 0,05 \\
\hline $\mathrm{Ca}$ & 0,29 & $\mathrm{Mg}$ & 0,04 \\
\hline $\mathrm{Si}$ & 0,17 & $\mathrm{Cu}$ & 0,01 \\
\hline $\mathrm{Fe}$ & 0,15 & $\mathrm{Br}$ & 0,01 \\
\hline $\mathrm{P}$ & 0,15 & $\mathrm{Mn}$ & 0,01 \\
\hline
\end{tabular}

Percebe-se na Tabela 1 que o bagaço de sorgo sacarino possui altos teores de voláteis e de carbono fixo e baixo teor de cinzas; características desejáveis para uma biomassa a ser pirolisada. Nota-se também que as quantidades tanto de magnésio quanto de zinco na biomassa pura são baixas, o que favorece a utilização desses sais no estudo da degradação térmica do sorgo sacarino.

\section{Adição de Sal a Biomassa}

$\mathrm{Na}$ preparação das amostras com aditivos inorgânicos, considerou-se a umidade da biomassa, o material foi mantido em estufa a $60^{\circ} \mathrm{C}$ para calcular o teor de umidade. Essa temperatura baixa de secagem foi adotada para evitar a volatilização de componentes da biomassa diferentes da água. $\mathrm{O}$ valor de umidade encontrado foi de $5,9 \pm 0,9 \%$, em base seca. Os cloretos de zinco (anidro P.A. Sigma Aldrich) e de magnésio (hexahidratado Sigma Aldrich) foram adicionados à biomassa nas concentrações mássicas de 5, 10 e $20 \%$ (tendo sido descontada a quantidade de água no $\left.\mathrm{MgCl}_{2}\right)$; concentrações utilizadas por Lou et al. (2011b).

Para se adicionar os sais inorgânicos a biomassa, a respectiva quantidade de aditivo foi pesada em um béquer e a ela foram adicionados $50 \mathrm{~mL}$ de água destilada e deionizada a $70^{\circ} \mathrm{C}$. A solução gerada foi transferida para um béquer com a quantidade de biomassa calculada. $O$ béquer que continha o sal inorgânico foi lavado com mais $50 \mathrm{~mL}$ de água destilada e deionizada a $70^{\circ} \mathrm{C}$, e a solução foi novamente transferida para o béquer com biomassa. Durante o processo de adição das soluções de sal foi realizada a mistura constante com agitador magnético para assegurar uma distribuição uniforme. Os béqueres com biomassa, aditivo inorgânico e água foram mantidos em estufa a $40^{\circ} \mathrm{C}$ durante $24 \mathrm{~h}$, posteriormente $60^{\circ} \mathrm{C}$ durante $24 \mathrm{~h}$ e $105^{\circ} \mathrm{C}$ durante $2 \mathrm{~h}$ até que toda água fosse evaporada e fosse obtida a fibra impregnada e seca. A secagem lenta foi adotada para reduzir a degradação da biomassa, que ocorreria significativamente caso temperaturas altas fossem mantidas por períodos estendidos.

\section{Análises Termogravimétricas}

As análises termogravimétricas, tanto para o bagaço de sorgo puro quanto para o impregnado com sais, foram realizadas em um analisador termogravimétrico modelo TGA/DTA DTG-60H, marca Shimadzu. O analisador termogravimétrico empregado possui balança analítica com sensibilidade de medida de $10^{-6} \mathrm{~g}$ e apresenta sensibilidade de $0,1^{\circ} \mathrm{C}$ para a medida de temperatura. Visando minimizar problemas de transferência de calor e massa, as partículas utilizadas foram passantes pela peneira de 100 mesh. As medidas foram executadas usando nitrogênio como gás de purga, vazão de $30 \mathrm{~mL} / \mathrm{min}$. Amostras de aproximadamente $6 \mathrm{mg}$ foram analisadas nos testes. 
Inicialmente, o material foi aquecido a $100^{\circ} \mathrm{C}$, com taxa de aquecimento de $50^{\circ} \mathrm{C} / \mathrm{min}$ (a taxa máxima de operação do equipamento), e mantido a essa temperatura por $30 \mathrm{~min}$, para eliminar a umidade. Após a secagem, o material foi aquecido a $900^{\circ} \mathrm{C}$ para avaliação da degradação térmica. Foi utilizada uma taxa de aquecimento de $25^{\circ} \mathrm{C} / \mathrm{min}$. Os testes foram feitos em triplicata. Dados de peso, tempo e temperatura foram registrados usando o software do equipamento, gerando dados de perda de massa (TG) e perda diferencial de massa (DTG). Os dados referentes aos primeiros 30 minutos de reação não foram processados, assim as variações de massa devido à perda de água não foram consideradas.

\section{RESULTADOS E DISCUSSÃO}

As Figuras 1 e 2 apresentam as curvas TG e DTG do sorgo sacarino puro juntamente com as curvas da fibra impregnada com $\mathrm{MgCl}_{2}$ e $\mathrm{ZnCl}_{2}$ nas concentrações 5\%, $10 \%$ e $20 \%$ $(\mathrm{m} / \mathrm{m})$ :

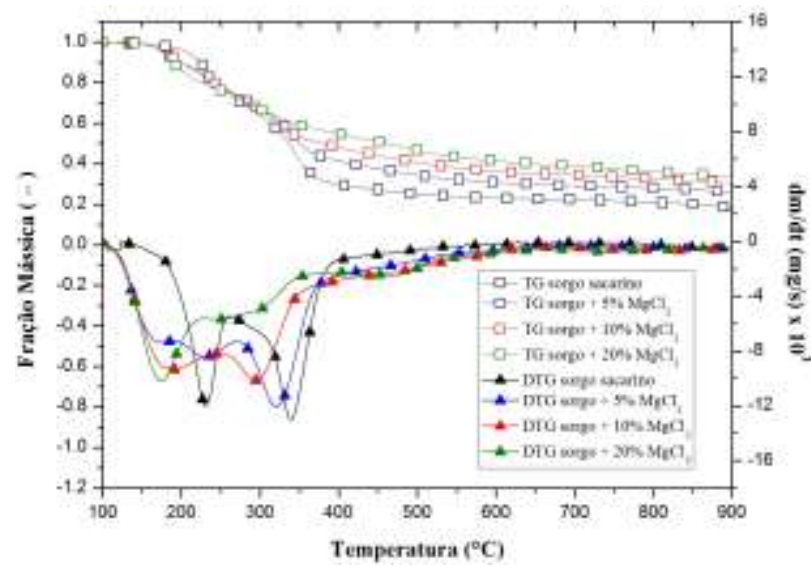

Figura 1 - Curvas TG e DTG para o sorgo sacarino puro e impregnado com $\mathrm{MgCl}_{2}$.

Analisando a Figura 1, observa-se o deslocamento das curvas de DTG para a esquerda, indicando um diminuição na temperatura de degradação com o aumento da porcentagem de $\mathrm{MgCl}_{2}$ impregnado. Esse efeito pode ser atribuído ao deslocamento de algumas reações de degradação da biomassa a uma temperatura mais baixa, indicando algum efeito catalítico do $\mathrm{MgCl}_{2}$. Segundo Khelfa et al. (2013) o cloreto de magnésio pode atuar na degradação da hemicelulose em baixas temperaturas de desidratação, despolimerização e de abertura do anel, levando à formação de produtos oxigenados leves. Este sal inorgânico pode afetar ainda a pirólise de alguns componentes da biomassa, diminuindo a temperatura máxima de pirólise e alterando a composição dos gases envolvidos, além de catalisar a desidratação primária da celulose e aumentando a quantidade de compostos produzidos a partir da hemicelulose, tendo um efeito insignificante sobre a pirólise da lignina.

Além disso, a presença do $\mathrm{MgCl}_{2}$ promove uma maior formação de char (Khelfa et al., 2008).

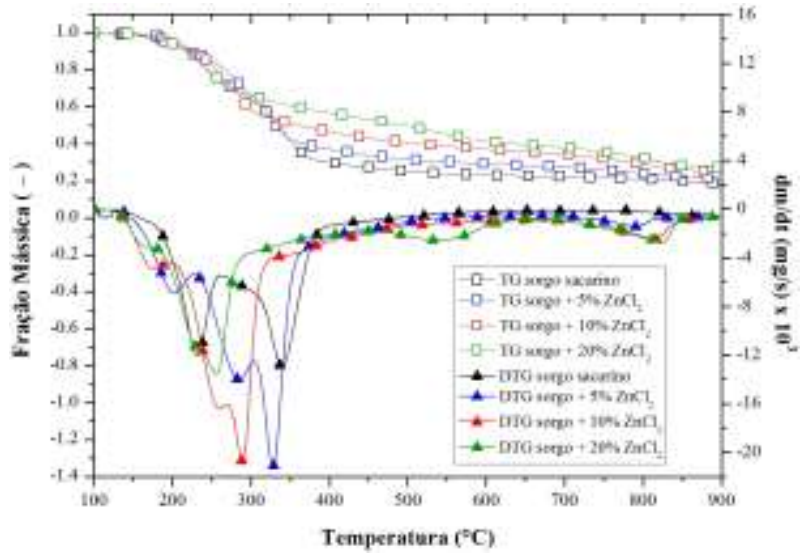

Figura 2 - Curvas TG e DTG para o sorgo sacarino puro e impregnado com $\mathrm{ZnCl}_{2}$.

Como observado na Figura 2, a adição de $\mathrm{ZnCl}_{2}$ causou uma grande modificação no perfil de degradação do sorgo, indicando uma diminuição na temperatura de decomposição com o aumento da porcentagem de sal impregnado. $\mathrm{O} \quad \mathrm{ZnCl}_{2}$ pode alterar significativamente as reações durante a pirólise de biomassa e de distribuição dos produtos, inibindo a desvolatilização da lignina, assim como a quebra do anel da holocelulose, podendo haver sua despolimerização e desidratação, aumentando a seletividade para compostos como furfural e levoglucosenona (Lu et al., 2010b).

Segundo Khelfa et al. (2008), $\mathrm{ZnCl}_{2}$ é um ácido de Lewis, que catalisa as quebras das ligações $\mathrm{C}-\mathrm{C}$ e $\mathrm{C}-\mathrm{O}$, atuando também em todas as vias de degradação da celulose: desidratação, despolimerização e abertura do anel, que conduz a formação de produtos oxigenados, de $\mathrm{CO}$ e $\mathrm{CO}_{2}$.

Lu et al. (2011b) também observaram decréscimos no teor de compostos fenólicos 
nos vapores pirolíticos de espiga de milho e madeira de álamo na medida em que a concentração de $\mathrm{ZnCl}_{2}$ era aumentada.

\section{CONCLUSÃO}

De acordo com as curvas TG e DTG, a adição tanto do $\mathrm{MgCl}_{2}$ quanto do $\mathrm{ZnCl}_{2}$ modificou o perfil de degradação da biomassa, indicando uma diminuição na temperatura de decomposição com o aumento da porcentagem de sal impregnado, podendo ser atribuído ao deslocamento de algumas reações de degradação do sorgo a uma temperatura mais baixa, indicando certo efeito catalítico de ambos os sais inorgânicos.

\section{REFERÊNCIAS}

BRIDGWATER, et al. Fast pyrolysis processes for biomass, Renewable and Sustainable Energy Reviews, Vol. 4, pp. 1-73, 2000.

CARDOSO, C. R., Efeito da temperatura e da adição de sais inorgânicos na pirólise analítica de resíduo de tabaco. 2013. 124p. Tese (Doutorado em Engenharia Química) - Universidade Federal de Uberlândia, 2013

EOM, IN-YONG et al. Effect of essential inorganic metals on primary thermal degradation of lignocellulosic biomass. Bioresource Technology, v. 104, p. 687-694, 2012.

GIANESELLA, M. Pyrolytic kinetics of lignocellulosic biomass. Tese (Doutorado em Engenharia Química) - Universidade Politécnica de Turim, 2010.

IONASHIRO, et al. Fundamentos da termogravimetria e análise térmica diferencial e calorimetria exploratória diferencial. São Paulo: Giz Editorial, 2005.

KHELFA, et al. Influence of some minerals on the cellulose thermal degradation mechanisms. Journal of Thermal Analysis and Calorimetry, v. 92, n. 3, p. 795-799, 2008.

KHELFA, A. et al.. Investigations into the pyrolytic behaviour of birch wood and its main components: Primary degradation mechanisms, additivity and metallic salt effects. Journal of Analytical and Applied Pyrolysis, 2013.

LINTON, J. A. et al. Economic feasibility of producing sweet sorghum as an ethanol feedstock in the southeastern United States. Biomass and Bioenergy, v. 35, n. 7, p. 3050-3057, 2011.

LU, Q. et al. Influence of pyrolysis temperature and time on the cellulose fast pyrolysis products: Analytical Py-GC/MS study. Journal of Analytical and Applied Pyrolysis, v. 92, n. 2, p. 430-438, 2011.

LU, Q. et al. Selective fast pyrolysis of biomass impregnated with $\mathrm{ZnCl} 2$ to produce furfural: Analytical Py-GC/MS study. Journal of Analytical and Applied Pyrolysis, v. 90, n. 2, p. 204-212, 2011.

RIEGEL, et al. Análise termogravimétrica da pirólise da acácia-negra (Acácia mearnsii de Wild.) cultivada no rio grande do sul brasil. Revista Árvore, v. 32, p. 533 - 543, 2008.

SHEN, D. K. et al. Study on the pyrolytic behaviour of xylan-based hemicellulose using TG-FTIR and Py-GC-FTIR. Journal of analytical and applied pyrolysis, v. 87, n. 2, p. 199 - 206, 2010.

VAMVUKA, et al., P. Pyrolysis characteristics and kinetics of biomass residuals mixtures with lignite. Fuel, v. 82, p. 1949-1960, 2003.

YAO, F. et al. Thermal decomposition kinetics of natural fibers: activation energy with dynamic thermogravimetric analysis. Polymer Degradation and Stability, v. 93, p. $90-98,2008$.

\section{AGRADECIMENTOS}

Os autores agradecem a FAPEMIG, CEMIG, CAPES e CNPq pelo apoio financeiro. 